\title{
Low Velocity Impact and Creep-Strain Behaviour of Vinyl Ester Matrix Nanocomposites Based on Layered Silicate
}

\author{
A. I. Alateyah, ${ }^{1,2}$ H. N. Dhakal, ${ }^{2}$ Z. Y. Zhang, ${ }^{2}$ and B. Aldousiri ${ }^{3}$ \\ ${ }^{1}$ Al Imam Mohammad Ibn Saud Islamic University (IMSIU), Riyadh 13318, Saudi Arabia \\ ${ }^{2}$ Advanced Polymer and Composites (APC) Research Group, School of Engineering, University of Portsmouth, \\ Portsmouth PO1 3DJ, UK \\ ${ }^{3}$ Department of Power and Desalination Plants, Ministry of Electricity, South Surra, 13001 Kuwait, Kuwait \\ Correspondence should be addressed to A. I. Alateyah; abdulrahman.alateyah@port.ac.uk
}

Received 6 July 2014; Accepted 17 October 2014; Published 6 November 2014

Academic Editor: Jan-Chan Huang

Copyright (C) 2014 A. I. Alateyah et al. This is an open access article distributed under the Creative Commons Attribution License, which permits unrestricted use, distribution, and reproduction in any medium, provided the original work is properly cited.

The impact properties of neat vinyl ester and the nanocomposites were performed using a low velocity impact testing. The addition of layered silicate into the polymer matrix shows that an optimum range of nanoclay reinforcement in the vinyl ester matrix can produce enhanced load bearing and energy absorption capability compared to the neat matrix. In addition, the amount of microvoids in the nanocomposites structure influences the overall properties. Likewise, the influence of the clay addition into the neat polymer on the creep relaxation behaviour at $25^{\circ} \mathrm{C}$ and $60^{\circ} \mathrm{C}$ was studied. In both cases, the presence of the layered silicate remarkably improved the creep behaviour. The improvement of these properties can be assigned to the stiff fillers and the configurational linkage between the polymer and the layered silicate which are supported by scanning electron microscopy (SEM) and transmission electron microscopy (TEM) characterisations by showing a distinct change in surface morphology associated with improved impact toughness and creep response.

\section{Introduction}

Polymer materials are widely used in different research and industrial fields, owing to their advantageous properties such as light weight and manufacturing simplicity. However, certain of the polymer properties are inadequate unless they are enhanced through incorporation of fillers and various reinforcements leading to the formation of composite or nanocomposite materials [1]. For that reason and to overcome these downsides, suitable additives are utilised in a host of pristine polymers in order to improve their properties [2].

Polymers with various additives have been successfully reinforced to improve their properties, such as mechanical, thermal, and barrier properties $[3,4]$. The presence of the particulate fillers often results in undesirable properties, such as brittleness and opacity. Also, the dispersion of the additive into the polymer is not homogenous [5].

Composite materials have a fairly new class of material nanocomposites that combine between fillers and matrix and in which at least one dimension of the dispersion particles is in the nanometer range. The use of nanocomposites prepared by a layered structure, like clays, has been the subject of elaborate research. However, the subject is experiencing resurgence, both in terms of academic research and industrial activity due to the numerous properties that nanocomposites stand to afford [6].

Polymer layered silicate nanocomposites usually provide more attractive enhancements to material properties than conventional composite materials [7-12]. The improvement of properties can be mechanical (strength, modulus, and hardness), thermal, or barrier properties [9, 13-18]. In addition, the polymer performance can be enhanced by the addition of layered silicate [19]. The percent of the nanofillers is usually less than $5 \mathrm{wt} . \%$ clay loading, which can enhance the engineering properties without sacrificing important properties such as optical and weight [20]. However, the impact properties are a big concern in the field of nanocomposites, where many studies noted a reduction of impact properties 
by the addition of layered silicate [21]. In some applications in hard working conditions, such as slide bearings, the impact properties are the main key to meet the requirements of these applications [22]. Thus, the study of the impact properties is fundamentally important for many polymers. In addition, another fundamental property is creep, which can be defined as the time dependent deformation of the materials that are subject to continuous load under the yielding stress of the materials. The deformation of creep can be either plastic or elastic, which may be nonrecoverable after the relaxation load. The creep can end up causing the material to have a structural failure, so the study of this property is important for different engineering designs [23].

Thermoset vinyl ester resin was used in this study due to its enhanced mechanical and chemical resistance properties. It is a middling choice between the epoxy and unsaturated polyester in terms of its properties and cost. However, the vinyl ester as a matrix has some drawbacks which include low resistance to crack propagation, brittleness, and shrinkage under polymerisation [24]. Thus, the primary objective of this study is to investigate the effect of the incorporation of the layered silicate into the vinyl ester matrix on the low velocity impact and creep-strain relaxation behaviour.

\section{Experimental}

2.1. Materials. The matrix material used in this study is vinyl ester (VE) resin. This material was purchased locally from Cathy Composites Portsmouth and commercially coded as AME $6000 \mathrm{~T} 35$. The layered silicate that has been used is Cloisite 10A which is classified as a natural montmorillonite that is modified with a quaternary ammonium salt.

\subsection{Sample Fabrication Process}

2.2.1. Neat Vinyl Ester. In order to make neat vinyl ester panels, the vinyl ester was directly mixed with the curing agent (MEKP) (mix ratio 1.5\%) and then was poured in a steel mould. The mould was closed and the composite panel was left to cure in a hydraulic press at a temperature of $55^{\circ} \mathrm{C}$ and at a compaction pressure of $1 \mathrm{MPa}$ for 2 hours.

2.2.2. Nanocomposites. Prior to this process, the layered silicate was dried for 3 hours at $120^{\circ} \mathrm{C}$ in a fan assisted oven. The vinyl ester resin was mixed with various concentrations of nanoclay at room temperature using a mechanical mixer in an ultrasonic bath for 2 hours. A degassing process was applied in the mixture for 3-4 hours and then it was left overnight in order to get rid of the remaining air bubbles naturally. A curing agent (MEKP) was added to the mixture (1.5\%). A Frekote mould release was utilised in order to easily remove the samples. The mould was closed and the composite panel was left to cure in a hydraulic press at a temperature of $55^{\circ} \mathrm{C}$ and at a compaction pressure of $1 \mathrm{MPa}$ for 2 hours. A postcuring process for 3 hours at $80^{\circ} \mathrm{C}$ followed. The concentrations of the layered silicate were $0,1,2,3,4$, and 5 wt.\%.

\subsection{Characterisation}

2.3.1. Wide Angle X-Ray Diffraction (WAXD). WAXD analysis on compression-moulded specimens was used to determine the clay intercalation and interlayer spacing utilising a Philips APD $1700 \mathrm{X}$-ray diffraction system with $\mathrm{Cu} \mathrm{K \alpha}$ radiation $(\lambda=1.542 \mathrm{~A})$ generated at $40 \mathrm{~mA}$ and $40 \mathrm{kV}$. The basal spacings (the d-spacing, in Angstroms, between layers) were calculated using Bragg's law.

2.3.2. Scanning Electron Microscopy (SEM). The morphology of vinyl ester/nanocomposite systems was investigated in a Hitachi S4500 SEM working at an operating voltage of $8 \mathrm{kV}$. Block faces were prepared from each material, and then ultrathin sections $(63 \mathrm{~nm})$ were collected using a diamond knife in a Reichert Ultracut $\mathrm{E}$ ultramicrotome. Plasma etching was used to preferentially remove the vinyl ester matrix and leave the clay particles sitting proud of the surface. After adhering to SEM stubs, a thin layer of gold/palladium was applied to the specimens prior to examination in a Quanta 250 FEG SEM.

2.3.3. Energy Dispersive X-Ray Spectrometry (EDS). The morphology of the VE/nanocomposite structure was further examined using a Jeol JSM 6060LV microscope working at an operating voltage of $8 \mathrm{kV}$. The degree of dispersion between the layered silicate and the vinyl ester matrix of the nanocomposite samples was measured using energy dispersive spectroscopy (EDS), a by-product of the backscattered electrons off the specimen from the electron beam. By scanning the beam in television-like raster and showing the intensity of the selected sample, a map (image) of the distribution of elements can be produced.

2.3.4. Transmission Electron Microscopy (TEM). TEM measurements on vinyl ester/nanocomposite systems were performed using a high-resolution transmission electron microscope (Phillips CM12 with an associated Gatan digital camera system). The same block faces used to produce the sections for SEM examination were also used for TEM.

\subsection{Testing}

2.4.1. Impact Test. The impact strength of the neat vinyl ester and the corresponding nanocomposite samples was determined by an instrumented falling weight impact tester (Zwick Roell, HIT230F). The annular hole diameter on the specimen fixture was approximately $4 \mathrm{~cm}$. The specimen dimension utilised for the impact test was $60 \mathrm{~mm} \times 60 \mathrm{~mm} \times 6 \mathrm{~mm}$. The total mass $(\mathrm{kg})$, work capacity $(\mathrm{J})$, and the height of release of the load (mm) were $23.11 \mathrm{~kg}, 25 \mathrm{~J}$, and $110 \mathrm{~mm}$, respectively. This process was carried out at room temperature. The energy absorption of the samples was calculated from the curve of the maximum force deformation. The incident energies were obtained from adjusting the drop height of the impactor and calculated using a typical energy equation:

$$
E_{i}=m g h,
$$


where $E_{i}$ is incident impact energy, $m$ is mass of the impactor, $g$ is gravity, and $h$ is height.

2.4.2. Creep Relaxation Behaviour. The creep test was carried out with the following parameters: $60 \mathrm{~N}$ loads, $25^{\circ} \mathrm{C}$ and $60^{\circ} \mathrm{C}$, and $96 \mathrm{hrs}$ period times. Neat polymer, $2 \mathrm{wt} . \%$, and $4 \mathrm{wt} . \%$ nanocomposite samples were investigated. The specimens were prepared as $20 \mathrm{~mm} \times 20 \mathrm{~mm} \times 6 \mathrm{~mm}$. This size sample was used in order to compare it with different mechanical tests such as tensile, flexural, and nanoindentation that have been already applied on the same geometry sample [6]. The initial and final strains of each sample were calculated from the strain-time curve.

\section{Results and Discussions}

\subsection{Characterisations of the Interlamellar Structure and Surface Morphology}

3.1.1. Wide Angle X-Ray Diffraction (WAXD). XRD values of the neat polymer and the corresponding nanocomposites can be seen in Table 1 and Figure 1. The Cloisite $10 \mathrm{~A}$ represents $20^{\circ}$ which indicates $0.443 \mathrm{~nm}$ basal distance. At $2 \mathrm{wt} \%$ clay loading, the angle was shifted toward a lower angle compared to Cloisite $10 \mathrm{~A}$ and showed $16.86^{\circ}$ which indicated $0.525 \mathrm{~nm}$, so the intercalation of the nanocomposite structure took place. The enhancement of the $\mathrm{d}$-spacing of the layered silicate of $2 \mathrm{wt} . \%$ was $16 \%$ compared to the pristine clay. At $4 \mathrm{wt} . \%$, the $2 \theta$ was much reduced compared to both neat clay and $2 \mathrm{wt} . \%$ and represents $13.84^{\circ}$ which indicated an intercalated basal spacing of $0.640 \mathrm{~nm}$. The enhancement of the interlayer spacing at $4 \mathrm{wt} . \%$ was about $45 \%$ compared to the $\mathrm{d}$-spacing of base clay. This enhancement in $\mathrm{d}$ spacing value at the $4 \mathrm{wt}$.\% reinforced samples indicated that the nanocomposites structure was intercalated or partially well-dispersed. In addition, the increment of basal distance indicated a good dispersion level of the clay into the polymer matrix. After the addition of more clay (i.e., 5 wt.\%), the $2 \theta$ value was $16.08^{\circ}$ and represented $0.551 \mathrm{~nm}$ of layered silicate spacing which was reduced compared to $4 \mathrm{wt} . \%$. The reduction of d-spacing of $5 \mathrm{wt}$.\% may be attributed to the high viscosity of the mixture where insufficient mixing might have taken place, so agglomeration layers were observed in the nanocomposite structure. A clear relationship between the gallery distance and the level of distribution of the layered silicate in the matrix is proved by the $2 \theta$ values.

3.1.2. Scanning Electron Microscopy (SEM). The SEM images in Figure 2 illustrate clearly the incorporation of the layered silicate through the vinyl ester for each of the three levels of loading. Because of the difference between the vinyl ester and the clay in scattering density, the large aggregation particles can be easily illustrated by SEM. As the selected images show below, the largest clay agglomerates are of a similar size for all three samples, being around 30 to 35 microns in size. However, their frequency increases with each larger clay volume fraction, as does the degree of infilling between them with smaller aggregation. It can be seen that the $2 \mathrm{wt} . \%$

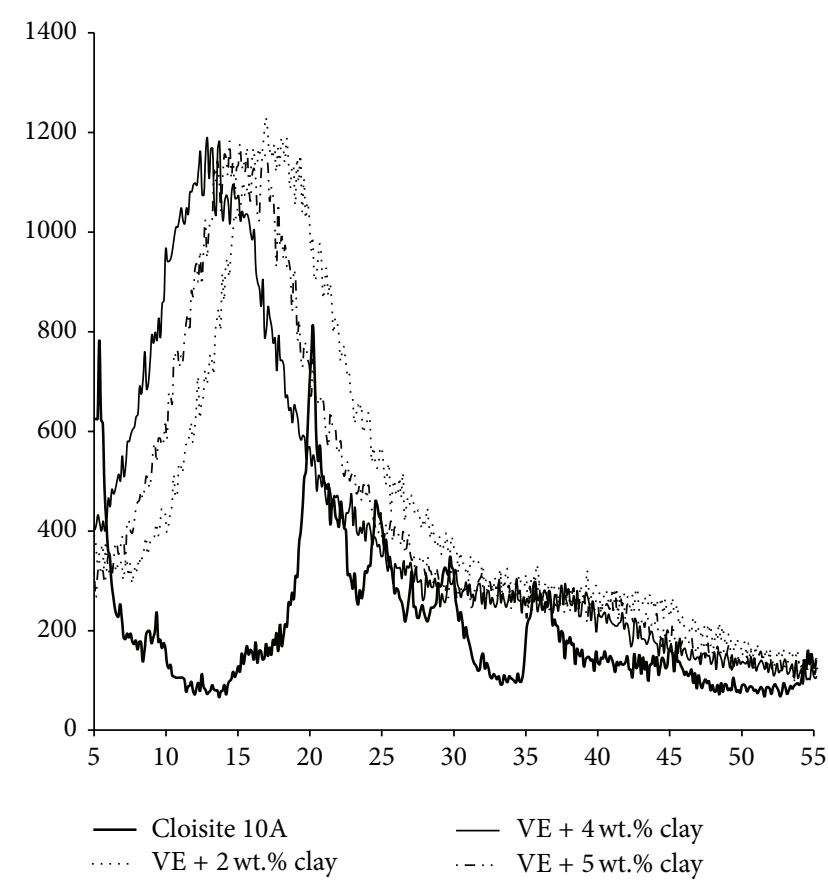

FIGURE 1: XRD results of neat polymer and the corresponding nanocomposites.

TABLE 1: XRD results obtained from different clay loading of nanocomposites.

\begin{tabular}{lccc}
\hline Sample number & $2 \theta$ values & $\begin{array}{c}\text { The interlayer } \\
\text { distances }(\mathrm{nm})\end{array}$ & $\begin{array}{c}\mathrm{d} \text {-spacing } \\
\text { improvement } \\
\%\end{array}$ \\
\hline Cloisite 10 A & 20.00 & 0.443 & 00.00 \\
Vinyl ester + 2 wt.\% clay & 16.86 & 0.525 & 18.51 \\
Vinyl ester + 4 wt.\% clay & 13.84 & 0.639 & 44.24 \\
Vinyl ester + 5 wt.\% clay & 16.08 & 0.551 & 24.38 \\
\hline
\end{tabular}

clay loading exhibits uniform distribution layers throughout the polymer sea. Likewise, the well-dispersed clay within the vinyl ester matrix and unpronounced aggregation of layered silicate took place at higher amounts of clay such as $4 \mathrm{wt} . \%$. The SEM image of $5 \mathrm{wt}$ \% clay loading provides a high number of stacked clay particles compared to those at 2$4 \mathrm{wt} . \%$. These findings are correlated with the results provided by XRD curves.

3.1.3. Energy Dispersive X-Ray Spectrometry (EDS). Figure 3 represents the incorporation of different fractions of layered silicate into the vinyl ester matrix. It was observed that the incorporation of the clay into the polymer sea was fairly homogeneous with a small amount of agglomerative layers at higher clay loading levels. Also, it was found that the enhancement of the clay loadings led to an increase in the amount of clay agglomeration which was attributed to the viscosity of the mixture. EDS represents the layered silicate as white points which reflected the Si element. At 2 wt.\% clay loading, the level of distribution of clay into the vinyl 


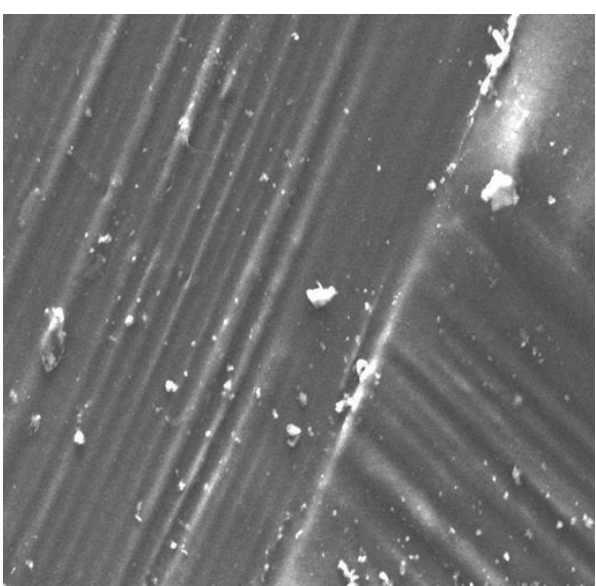

(a)

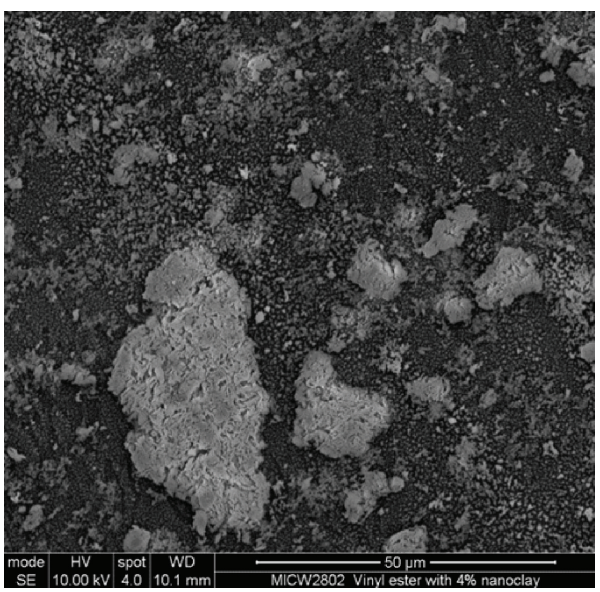

(c)

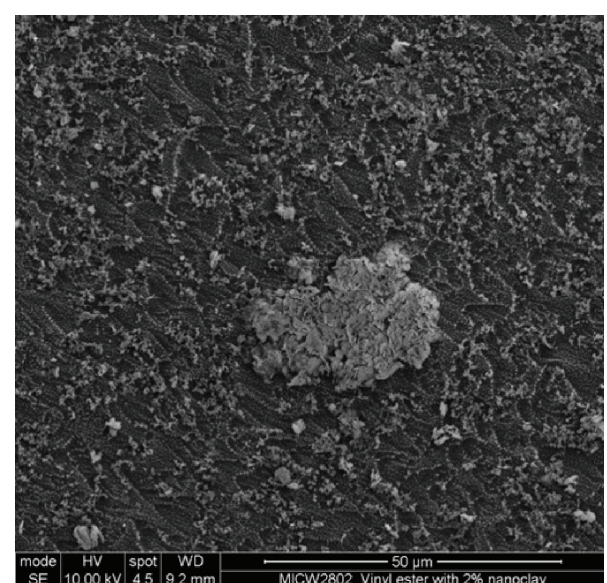

(b)

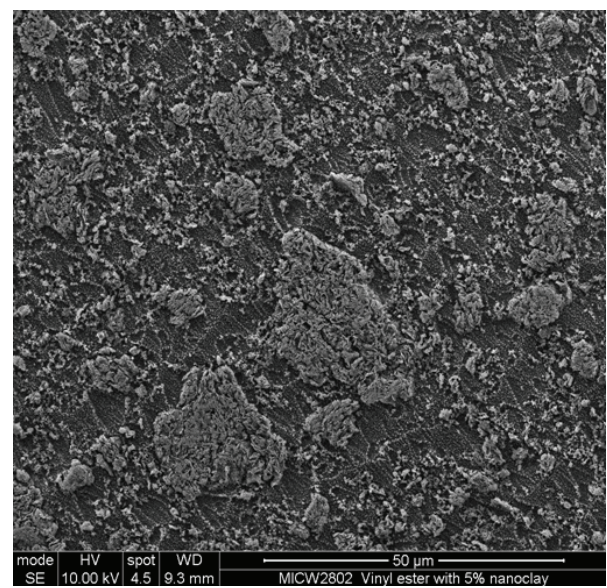

(d)

Figure 2: SEM images at $50 \mu \mathrm{m}$ of (a) neat vinyl ester, (b) $2 \mathrm{wt} . \%$, (c) $4 \mathrm{wt} . \%$, and (d) $5 \mathrm{wt} . \%$ nanocomposites.

ester matrix was uniform and no agglomeration layers were observed at 55x magnification of EDS. By the presence of more clay (i.e., 4 wt.\%), the nanocomposite structure exhibited a reasonable intercalation/exfoliation structure although the aggregation of a few layers was obtained. In addition, the incorporation of high amounts of clay such as $5 \mathrm{wt} . \%$ led to reducing the homogeneity and increasing the aggregation and the microvoids in the nanocomposite structure. These results explain the reduction in the d-spacing value as was calculated by XRD and confirmed the results by SEM.

3.1.4. Transmission Electron Microscopy (TEM). Figure 4 shows the TEM micrographs of 2, 4, and 5 wt.\% nanocomposite samples at $50 \mathrm{~nm}$, where the bright area corresponds to the matrix sea and the dark lines signify the stacked or individual silicate layers. Indications from the higher magnification images are that greater levels of exfoliation nanocomposites are achieved with lower nanoclay loading. At 2 wt.\% clay loading, the TEM image exhibits uniform distribution of layered silicate throughout the vinyl ester matrix. An intercalated/exfoliated structure is observed at 4 wt.\% clay loading, as seen in Figure 4 . The layered silicate shows well-dispersed clay with a few aggregation layers. At 5 wt.\% clay loading, additional dark regions are observed which indicate the aggregation of silicate layers and insufficient dispersion. TEM images conclude that the particle lumps (agglomeration) are increased by the addition of more than 4 wt.\% clay loading. This was attributed to the high viscosity of the mixture where the ability to mix the layered silicate and the polymer is restricted. It is acceptable that the higher the amount of clay loading mixed with the polymer, the less exfoliated and aggregated the nanocomposite structure $[25,26]$. These outcomes support the results by XRD, SEM, and EDS.

3.2. Low Velocity Impact Response. In this study, the falling weight impact tests, which are the most common for composite and nanocomposite materials, were carried out on the neat vinyl ester and the corresponding nanocomposites. Different clay concentrations were used which included 2, 4, and $5 \mathrm{wt} . \%$ clay loading. The impact test was used in order to analyse and evaluate the effect of the incorporation of layered silicate into the polymer matrix. Many parameters can be calculated from this test, such as the maximum force 


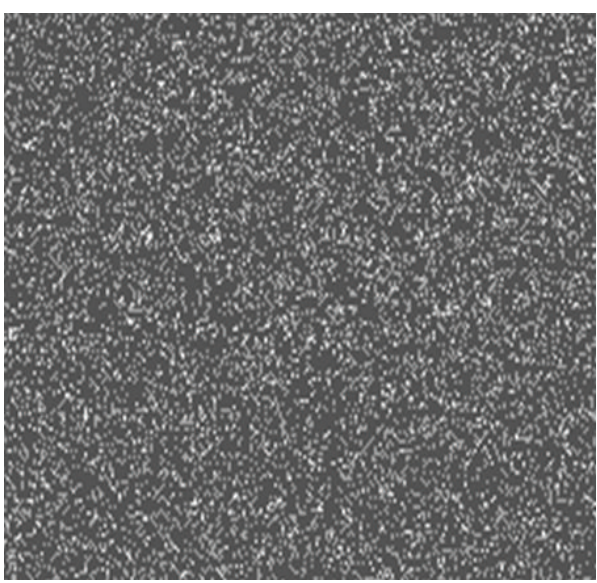

(a)

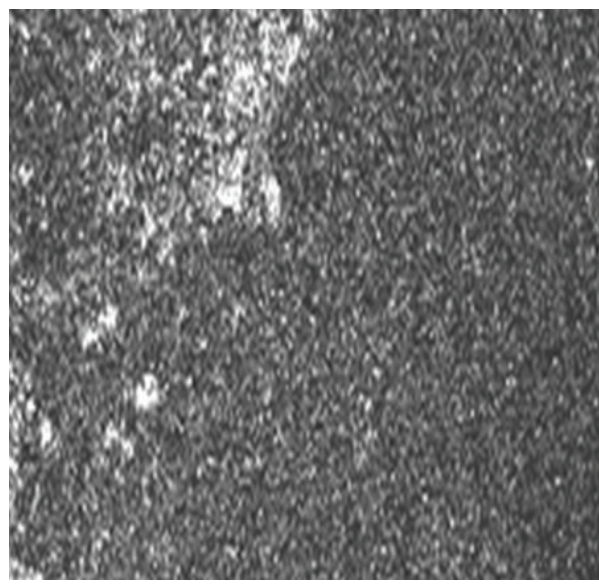

(c)

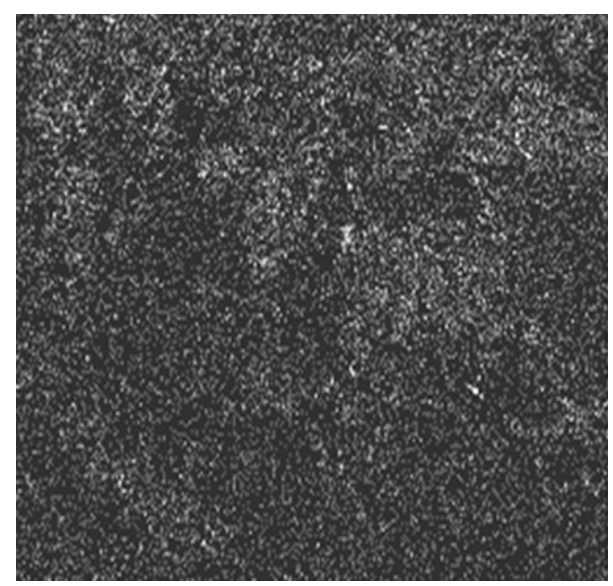

(b)

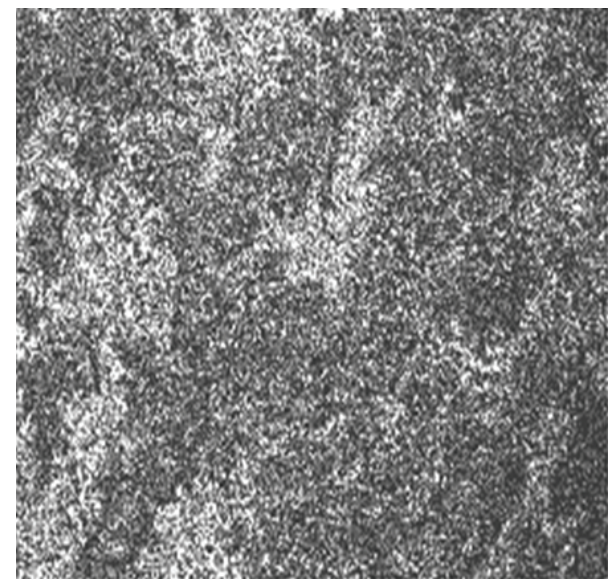

(d)

FIGURE 3: EDS images at 55x magnification of (a) neat vinyl ester (Cl element), (b) 2 wt.\% (Si element), (c) 4 wt.\% (Si element), and (d) 5 wt.\% (Si element) nanocomposites.

$(\mathrm{N})$ and energy absorption (J) in a function of time (ms) curve. Four specimens from each group were tested and the average values were calculated as seen in Table 2. From Table 2, although the amount of load was high, the effect of the incorporation of the layered silicate into the vinyl ester matrix was observable and the addition of clay resulted in enhancing the impact properties. The maximum force and energy absorption were increased up to $42 \%$ and $59.74 \%$ respectively at $4 \mathrm{wt} . \%$ clay loading. The improvements of the maximum load and energy were proportional to the amount of the clay loading; however, at higher amounts of clay loading such as $5 \mathrm{wt} . \%$, the force and energy absorption decreased compared to the 4 wt.\% clay concentration, as seen in Figures 5 and 6 . These results indicated that the addition of nanofillers to the polymer matrix not only increases the strength of the output product but also increases the toughness.

One reason for the enhancement of the impact properties can be traced to the existence of microvoids while mixing the nanolayers and the polymer. When the impact load was applied, the microvoids initiated the shear yielding of the combinations of vinyl ester polymer and the layered silicate throughout the whole volume and at the start of the crack propagation. Thus, the shear yielding distributed the mechanical stress and enhanced the strength and toughness of the nanocomposites by absorbing the energy [27]. Nanocomposites voids were calculated by using the following equation:

$$
V_{v}=\rho_{n}\left(\frac{w_{c}}{\rho_{c}}+\frac{w_{m}}{\rho_{m}}\right),
$$

where $V_{v}$ is the volume fraction of voids, $\rho_{n}$ is the density of nanocomposites, $w_{c}$ is the weight percent of clay (\%), $\rho_{c}$ is the density of clay $\mathrm{g} / \mathrm{cm}^{3}(0.16), w_{m}$ is the weight percent of matrix (\%), and $\rho_{m}$ is the density of matrix $\mathrm{g} / \mathrm{cm}^{3}$. The density of nanocomposites was calculated as follows:

$$
\rho_{n}=\rho_{c} w_{c}+\rho_{m} w_{m}
$$

The voids content in nanocomposites felid is a big concern for the industrial or engineering designs. The pre-failure and the promoting of the local deformation of the applications can be obtained by the existence of high content of microvoids [28]. Thus the study of the parameters influences the content voids 
TABLE 2: Impact test results of neat polymer and the corresponding of nanocomposites.

\begin{tabular}{lcccc}
\hline Samples & $F_{\max }(\mathrm{N})$ & $\begin{array}{c}\text { Improvement of } \\
\text { the peak load (\%) }\end{array}$ & $\begin{array}{c}\text { Energy (J) } \\
\text { Improvement of } \\
\text { the energy } \\
\text { absorption (\%) }\end{array}$ \\
\hline Neat vinyl ester & $1327 \pm 9.00$ & 0 & $1.54 \pm 0.38$ & 0 \\
Vinyl ester + 2 wt.\% clay loading & $1501 \pm 8.80$ & 13.11 & $1.83 \pm 0.31$ & 18.9 \\
Vinyl ester + 4 wt.\% clay loading & $1885 \pm 9.00$ & 42.05 & $2.46 \pm 0.30$ & 59.74 \\
Vinyl ester + 5 wt.\% clay loading & $1655 \pm 10.0$ & 24.72 & $1.95 \pm 0.33$ & 21.03 \\
\hline
\end{tabular}

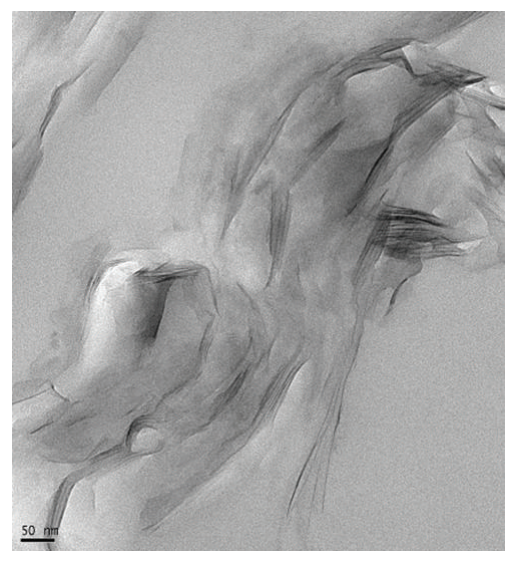

(a)

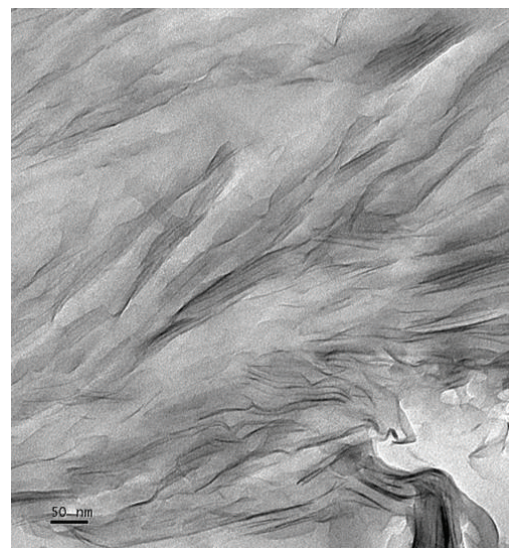

(b)

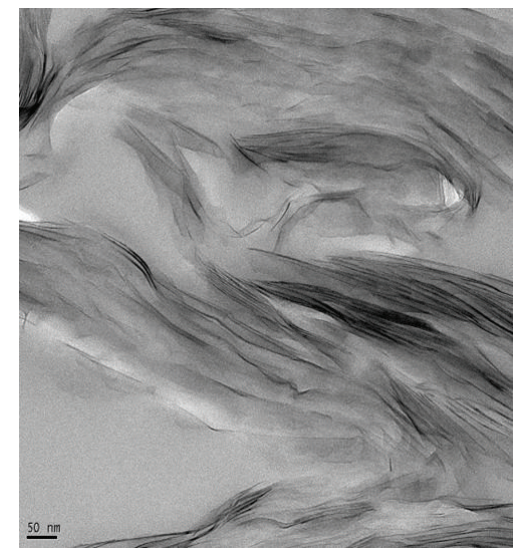

(c)

Figure 4: TEM micrographs at $50 \mathrm{~nm}$ magnification of (a) $2 \mathrm{wt} . \%$, (b) $4 \mathrm{wt} . \%$, and (c) $5 \mathrm{wt} . \%$ nanocomposites.

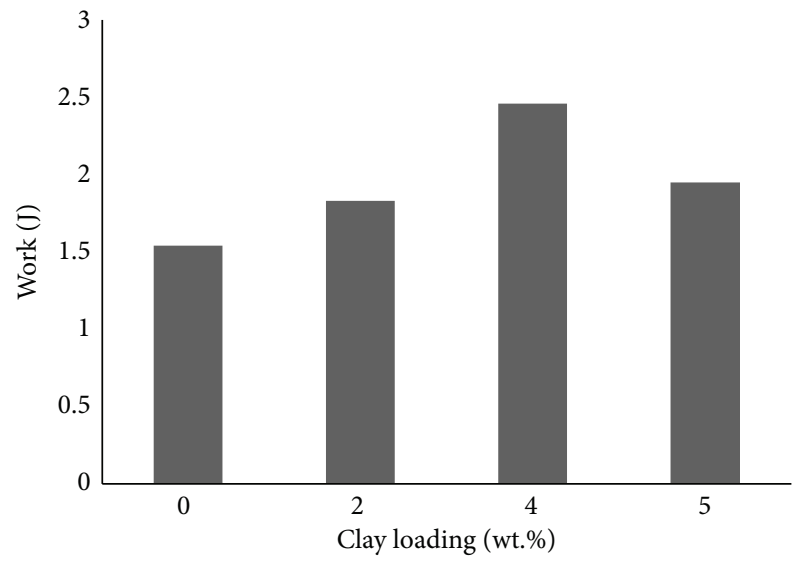

FIGURE 5: The relation between the work (J) and the clay loading wt.\%.

TABLE 3: Voids content of different nanocomposites samples.

\begin{tabular}{lcc}
\hline Sample & Void content (\%) & Percentages (\%) \\
\hline Vinyl ester + 2 wt.\% clay & 2.45 & 1.32 \\
Vinyl ester + 4 wt.\% clay & 6.40 & 5.06 \\
Vinyl ester + 5 wt.\% clay & 9.03 & 7.55 \\
\hline
\end{tabular}

as well as the percentage of these values can help to protect the presence of such drawback.

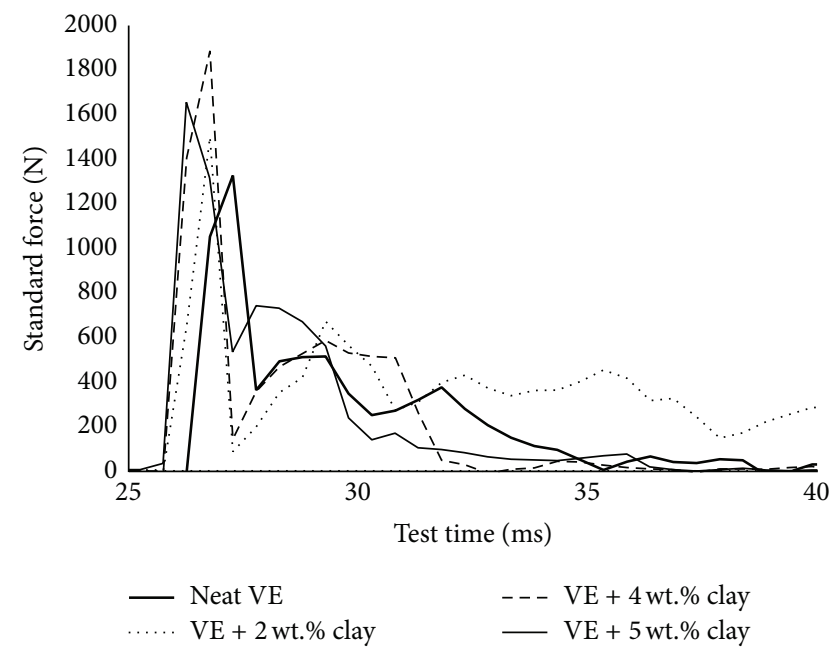

FIGURE 6: Maximum force versus time traces of the impact test.

From (2) and (3), the voids content in the nanocomposites sample was calculated and presented in Table 3. It can be seen that the voids percentage was proportional to the clay content. Maximum voids volume was found at $5 \mathrm{wt}$ \% clay loading which represented $9.03 \%$. The voids percentage can conclude that the acceptable voids content regards that the impact properties in the existence parameters used are to be less than $6.5 \%$ volume. Otherwise, less interfacial interaction between the layered silicate and the polymer will take place. Also, it 


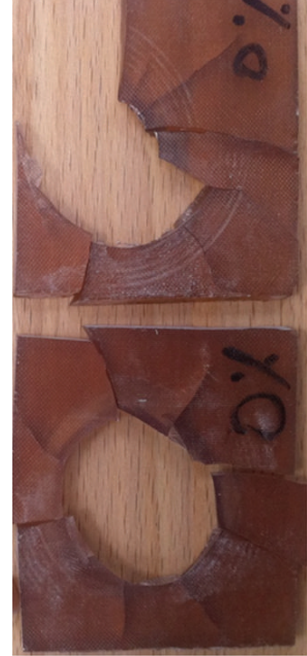

(a)

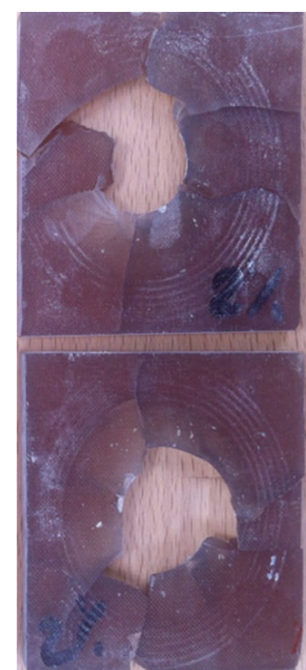

(b)

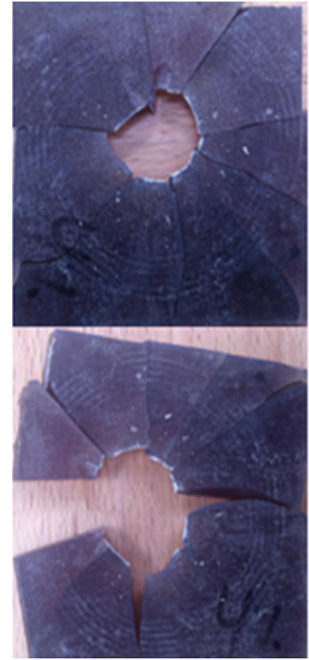

(c)

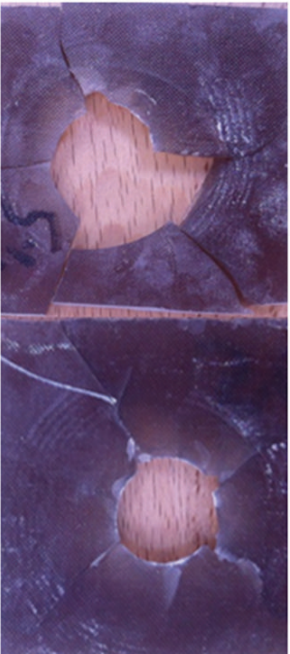

(d)

FIGURE 7: Fragmentation characteristics of (a) neat vinyl ester, (b) nanocomposites of 2 wt.\% clay loading, (c) nanocomposites of 4 wt.\% clay loading, and (d) nanocomposites of $5 \mathrm{wt} . \%$ clay loading.

may be noted that the tortuous path of the clay layers when the interface between them took place played an important role in the distribution of the mechanical stress applied. As concluded by SEM, the distance between particles and clay volume has an inverse relationship where the distance is decreased by the addition of more clay. Thus, the tortuous path is increased and the crack propagation would take a longer path. This phenomenon explains the improvement of the impact properties at $4 \mathrm{wt} . \%$ compared to $2 \mathrm{wt} . \%$. As a result, the intercalation system can provide better impact properties than the exfoliation system [29].

At $5 \mathrm{wt} . \%$ clay loading, the impact properties were reduced which was ascribed to the presence of the aggregation layers where the stress concentration factor was high. When the stress concentration factor is high, the initiation of premature failure may happen. In addition, the microvoids have contradictory functions regarding the impact properties. Fewer amounts of microvoids will allow the yield shielding of the applied load to be presented. However, the high amount of microvoids (i.e., $5 \mathrm{wt} . \%$ ) will reduce the interfacial interaction between the polymer and layered silicate, so premature failure will dominate. Although the reduction of impact properties at high loadings of clay was observed, still there was an improvement compared to neat vinyl ester. This study was in close agreement to the report conducted by Lin et al. [30].

The results can be correlated to the SEM. Figure 2 shows the SEM images of neat matrix and the corresponding nanocomposite. It can be seen that the nanocomposite samples had microphases in their structure, whereas the neat matrix showed a smooth glassy structure, which was attributed to the brittleness of the material.

3.2.1. Fragmentation Characteristics. The impact fracture shapes of different samples are shown in Figure 7. As can be seen, the neat polymer exhibited brittle fractures as the samples were fragmented when undergoing the impact load. The diameter of the hole presented by the impact force for neat vinyl ester was almost $40 \mathrm{~mm}$. At $2 \mathrm{wt} . \%$ clay loading, the nanocomposite samples showed better impact stability compared to neat polymer. The samples were not wholly fragmented upon impact force. The hole diameter of the 2 wt.\% nanocomposite was less than neat polymer which presented about $30 \mathrm{~mm}$. The best impact resistance was found at $4 \mathrm{wt} . \%$ clay loading where the samples showed only about a $25 \mathrm{~mm}$ hole. At $5 \mathrm{wt} . \%$ nanocomposites, the sample showed less stability upon the impact load compared to the $4 \mathrm{wt} . \%$ clay loading and exhibited about a $30-40 \mathrm{~mm}$ diameter hole.

3.3. Creep-Strain Relaxation Behaviour. The creep relaxation measurement is a key for understanding the performance of the product and the material processing. The test can help to evaluate the material's solid-like behaviour and the effect of the incorporation of layered silicate into the polymer matrix into the creep properties. In this test, the samples were subjected to a constant load and the deformation levels were calculated in a function of time. The stress relaxation processes provide an insight into the viscoelastic behaviour of the material.

Table 4 summarises the creep relaxation behaviour of neat vinyl ester and the corresponding nanocomposites at $25^{\circ} \mathrm{C}$ and $60^{\circ} \mathrm{C}$. At $25^{\circ} \mathrm{C}$, the elastic response of the nanocomposite samples exhibited less disturbance in terms of shear flow as seen in Figure 8. From the figure, it can be seen that the pristine polymer presented higher interval time and imposed stress. The initial part of the curve is termed "creep curve" and the remaining behaviour is called "relaxation level." According to the creep data, the strain reduction is proportional to the clay concentration level. The neat polymer illustrated higher strain compared to the nanocomposite 
TABLE 4: The strain amount of the neat vinyl ester and the corresponding nanocomposites during the creep test at different interval times and temperatures.

\begin{tabular}{lcccccccccc}
\hline \multirow{2}{*}{ Sample } & \multicolumn{3}{c}{ Initial strain (\%) } & \multicolumn{3}{c}{ Strain at 40 hours (\%) } & \multicolumn{2}{c}{ Strain at 60 hours (\%) } & Strain at 80 hours (\%) & \multicolumn{2}{c}{ Strain at 95 hours (\%) } \\
& $25^{\circ} \mathrm{C}$ & $60^{\circ} \mathrm{C}$ & $25^{\circ} \mathrm{C}$ & $60^{\circ} \mathrm{C}$ & $25^{\circ} \mathrm{C}$ & $60^{\circ} \mathrm{C}$ & $25^{\circ} \mathrm{C}$ & $60^{\circ} \mathrm{C}$ & $25^{\circ} \mathrm{C}$ & $60^{\circ} \mathrm{C}$ \\
\hline Neat vinyl ester & 23 & 17 & 25 & 21 & 26 & 22 & 26 & 22 & 26.3 \\
Vinyl ester + 2 wt.\% clay & 17 & 13 & 17.2 & 13.2 & 17.3 & 13.3 & 17.5 & 13.4 & 18 \\
Vinyl ester + 4 wt.\% clay & 14 & 12 & 14.2 & 12 & 14.4 & 12.1 & 14.6 & 12.2 & 13.6 \\
\hline
\end{tabular}

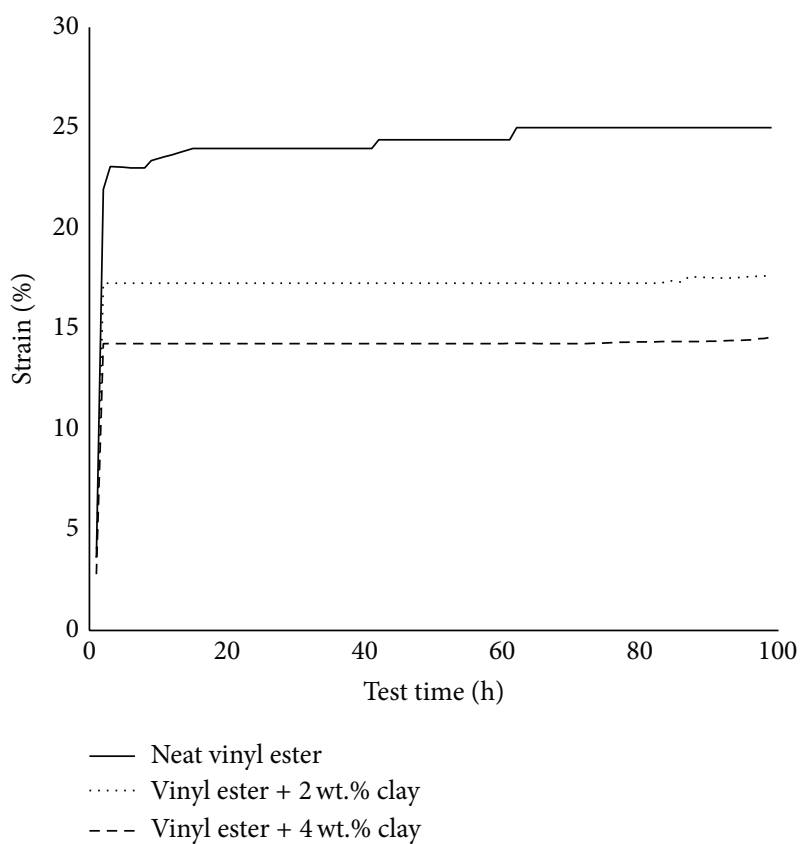

FIGURE 8: Creep relaxation behaviour of neat polymer and the corresponding nanocomposites at $25^{\circ} \mathrm{C}$.

samples where the strain started at $23 \%$ whereas 2 wt. $\%$ and 4 wt. $\%$ nanocomposites showed $17 \%$ and $14 \%$, respectively. In addition, the strain of the neat polymer started to increase after 40 hours by $2 \%$, which was attributed to the temperature. However, the nanocomposites were almost stable during the mechanical stress applied and the temperature. The enhancement of the creep properties depends on many reasons, such as the level of intercalation between the clay and polymer, the clay source, and the clay shape [31]. The microstructural changes in the clay suspension can also help to improve the creep behaviour. In addition, the presence of the layered silicate helps to improve the microphase separation, so enhancement of the elasticity took place and the reduction of the stress relaxation process was observed. Also, the layered silicate restricted the motion of the polymer chains which help to withstand the mechanical stress.

A similar test of the previous creep behaviour was undertaken at $60^{\circ} \mathrm{C}$ in order to evaluate the influence of the temperature on the neat and nanocomposite samples. Table 4 and Figure 9 show the creep relaxation behaviour of the selected samples. In the same case as the $25^{\circ} \mathrm{C}$, the nanocomposites exhibited good stability under the imposed

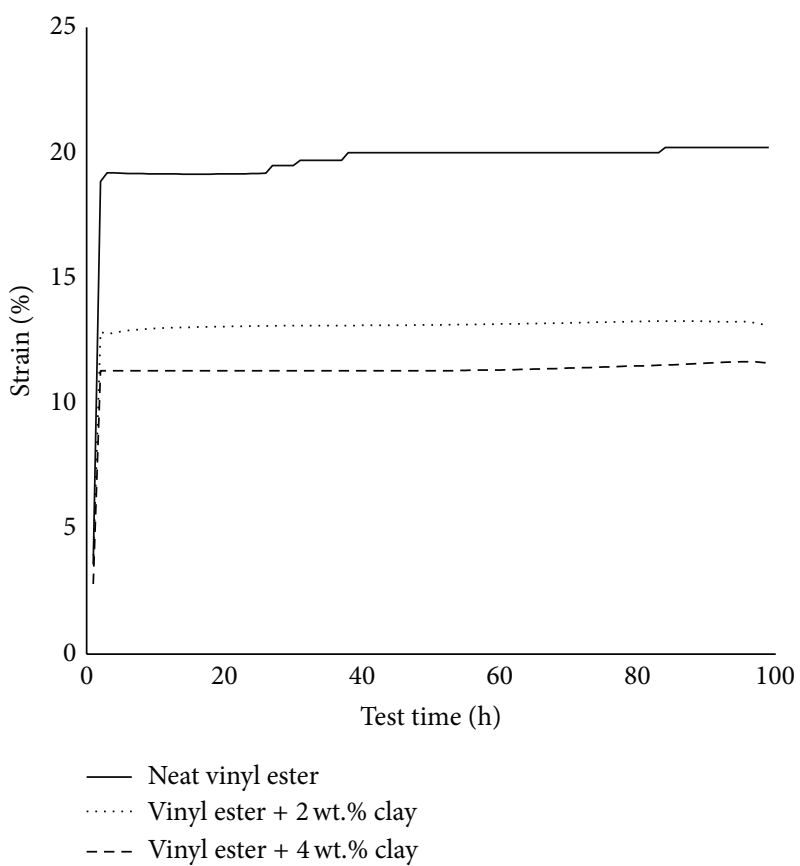

FIGURE 9: Creep relaxation behaviour of pristine matrix and 2 and 4 wt.\% nanocomposites at $60^{\circ} \mathrm{C}$.

stress. The higher temperature (i.e., $60^{\circ} \mathrm{C}$ ) represents better creep behaviour of the nanocomposite samples compared to $25^{\circ} \mathrm{C}$, which may be attributed to the thermodynamic barrier where the enthalpic gain is translated into entropic gain. Thus, enhancement of the conformational links between the layered silicate and polymer took place [32]. Also, the vinyl ester may be reorienting itself into a more ordered or compact structure resulting in a stronger cross-linking plastic at higher temperature. It can be seen that the neat vinyl ester started to be deformed at $17 \%$ of strain enlargement, whereas $2 \mathrm{wt} . \%$ and $4 \mathrm{wt} . \%$ clay loading represented an initial deformation at $13 \%$ and $12 \%$, respectively. The neat polymer showed less stability where the temperature affected the sample and led to increase the deformation by $20.5 \%$ at 40 hours. At 83 hours, the base vinyl ester started again to deform and the strain increased by $22 \%$. However, the nanocomposites exhibited almost the same deformation level at the initial and end time.

\section{Conclusion}

The layered silicate plays an important role in terms of the polymer properties. With the addition of only small 
amounts of clay, the impact and creep relaxation behaviours were remarkably increased compared to the neat polymer. As far as low velocity impact strength is concerned, the introduction of layered silicate contributed to increased loadbearing capability and better energy absorption compared to the neat vinyl ester samples even with the high amount of mechanical load applied. The microvoids that existed in the nanocomposites structure had contradiction function regarding the impact properties. The first one is initiating the yield shielding upon propagation at low voids content (less than 6.5\%), in turn, the crack paths will be distributed and altered by theses voids. At higher voids content, the premature failure will be obtainable due to the less interfacial interaction between the layered silicate and the polymer. The creep behaviour at both low and high temperatures, such as $25^{\circ} \mathrm{C}$ and $60^{\circ} \mathrm{C}$, represented an improvement in the nanocomposites and the enhancement was proportional to the clay content. These improvements were due to the addition of stiff fillers, where the imposed stresses can be shared by the layered silicate and the polymer. Also, the tortuous path of the clay can distribute the transferred load and restrict the motion of the polymer chains. Thus, the strain during constant load and temperature showed better stability in the nanocomposites than the neat polymer.

\section{Conflict of Interests}

The authors declare that there is no conflict of interests regarding the publication of this paper.

\section{References}

[1] T. Yu, Y. Li, and J. Ren, "Preparation and properties of short natural fiber reinforced poly(lactic acid) composites," Transactions of Nonferrous Metals Society of China, vol. 19, no. 3, pp. s651s655, 2009.

[2] A. I. Alateyah, H. N. Dhakal, and Z. Y. Zhang, "Processing, properties, and applications of polymer nanocomposites based on layer silicates: a review," Advances in Polymer Technology, vol. 32, no. 4, Article ID 21368, 2013.

[3] S. K. Swain and A. I. Isayev, "PA6/Clay nanocomposites by continuous sonication process," Journal of Applied Polymer Science, vol. 114, no. 4, pp. 2378-2387, 2009.

[4] B. Aldousiri, H. N. Dhakal, S. Onuh, Z. Y. Zhang, N. Bennett, and M. O. W. Richardson, "Effect of layered silicate reinforcement on the structure and mechanical properties of spent polyamide-12 nanocomposites," Composites Part B: Engineering, vol. 43, no. 3, pp. 1363-1367, 2012.

[5] L. Matějka, "Epoxy-silica/silsesquioxane polymer nanocomposites," in Hybrid Nanocomposites for Nanotechnology, pp. 184, Springer, Berlin, Germany, 2009.

[6] A. I. Alateyah, H. N. Dhakal, and Z. Y. Zhang, "Water absorption behaviour, mechanical and thermal properties of vinyl ester matrix nanocomposites based on layered silicate," PolymerPlastics Technology and Engineering, vol. 53, no. 4, pp. 327-343, 2014.

[7] A. B. Morgan and J. W. Gilman, "Characterization of polymerlayered silicate (clay) nanocomposites by transmission electron microscopy and X-ray diffraction: a comparative study," Journal of Applied Polymer Science, vol. 87, no. 8, pp. 1329-1338, 2003.
[8] H. Chen, M. Zheng, H. Sun, and Q. Jia, "Characterization and properties of sepiolite/polyurethane nanocomposites," Materials Science and Engineering A, vol. 445-446, pp. 725-730, 2007.

[9] M. Okamoto, Polymer/Layered Silicate Nanocomposites, Rapra Technology Limited, Shrewsbury, UK, 2003.

[10] S. S. Ray and M. Okamoto, "Polymer/layered silicate nanocomposites: a review from preparation to processing," Progress in Polymer Science, vol. 28, no. 11, pp. 1539-1641, 2003.

[11] S. K. Samudrala and S. Bandyopadhyay, "Development of development of hybrid nanocomposites for electronic applications," in Hybrid Nanocomposites for Nanotechnology, pp. 231-287, 2009.

[12] S. Lapshin, S. K. Swain, and A. I. Isayev, "Ultrasound aided extrusion process for preparation of polyolefin-clay nanocomposites," Polymer Engineering and Science, vol. 48, no. 8, pp. 1584-1591, 2008.

[13] S. Bathula, R. C. Anandani, A. Dhar, and A. K. Srivastava, "Microstructural features and mechanical properties of $\mathrm{Al}$ $5083 / \mathrm{SiC}_{p}$ metal matrix nanocomposites produced by high energy ball milling and spark plasma sintering," Materials Science and Engineering A, vol. 545, pp. 97-102, 2012.

[14] S. Lapshin and A. I. Isayev, "Continuous process for melt intercalation of PP-clay nanocomposites with aid of power ultrasound," Journal of Vinyl and Additive Technology, vol. 12, no. 2, pp. 78-82, 2006.

[15] Q. T. Nguyen and D. G. Baird, "Preparation of polymer-clay nanocomposites and their properties," Advances in Polymer Technology, vol. 25, no. 4, pp. 270-285, 2006.

[16] S. K. Patra, G. Prusty, and S. K. Swain, "Ultrasound assisted synthesis of PMMA/clay nanocomposites: study of oxygen permeation and flame retardant properties," Bulletin of Materials Science, vol. 35, no. 1, pp. 27-32, 2012.

[17] A. I. Alateyah, H. N. Dhakal, and Z. Y. Zhang, "Mechanical and thermal properties characterisation of vinyl ester matrix nanocomposites based on layered silicate," World Academy of Science, Engineering and Technology, vol. 81, pp. 1-8, 2013.

[18] F. C. Liu, E. H. Han, W. Ke et al., "Polar influence of the organic modifiers on the structure of montmorillonite in epoxy nanocomposites," Journal of Materials Science and Technology, vol. 29, no. 11, pp. 1040-1046, 2013.

[19] T.-T. Doan, H. Brodowsky, and E. Mäder, "Jute fibre/polypropylene composites II. Thermal, hydrothermal and dynamic mechanical behaviour," Composites Science and Technology, vol. 67, no. 13, pp. 2707-2714, 2007.

[20] B. K. Deka and T. K. Maji, "Study on the properties of nanocomposite based on high density polyethylene, polypropylene, polyvinyl chloride and wood," Composites Part A: Applied Science and Manufacturing, vol. 42, no. 6, pp. 686-693, 2011.

[21] T. D. Fornes, P. J. Yoon, H. Keskkula, and D. R. Paul, "Nylon 6 nanocomposites: the effect of matrix molecular weight," Polymer, vol. 42, no. 25, pp. 9929-9940, 2001.

[22] B. Wetzel, F. Haupert, K. Friedrich, M. Q. Zhang, and M. Z. Rong, "Impact and wear resistance of polymer nanocomposites at low filler content," Polymer Engineering and Science, vol. 42, no. 9, pp. 1919-1927, 2002.

[23] P. Domone and J. Illston, Construction Materials: Their Nature and Behaviour, Taylor \& Francis, New York, NY, USA, 2010.

[24] A. Almagableh, P. R. Mantena, A. Alostaz, W. Liu, and L. T. Drzal, "Effects of bromination on the viscoelastic response of vinyl ester nanocomposites," Express Polymer Letters, vol. 3, no. 11, pp. 724-732, 2009. 
[25] X. Liu and Q. Wu, "PP/clay nanocomposites prepared by grafting-melt intercalation," Polymer, vol. 42, no. 25, pp. 10013-10019, 2001.

[26] J. Jordan, K. I. Jacob, R. Tannenbaum, M. A. Sharaf, and I. Jasiuk, "Experimental trends in polymer nanocomposites-a review," Materials Science and Engineering A, vol. 393, no. 1-2, pp. 1-11, 2005.

[27] G. Hartwig, "Fracture behavior of polymers," in Polymer Properties at Room and Cryogenic Temperatures, pp. 187-218, Springer, New York, NY, USA, 1994.

[28] P. Ladeveze, "A damage computational approach for composites: basic aspects and micromechanical relations," Computational Mechanics, vol. 17, no. 1-2, pp. 142-150, 1995.

[29] A. S. Zerda and A. J. Lesser, "Intercalated clay nanocomposites: morphology, mechanics, and fracture behavior," Journal of Polymer Science, Part B: Polymer Physics, vol. 39, no. 11, pp. 11371146, 2001.

[30] J. C. Lin, L. C. Chang, M. H. Nien, and H. L. Ho, "Mechanical behavior of various nanoparticle filled composites at lowvelocity impact," Composite Structures, vol. 74, no. 1, pp. 30-36, 2006.

[31] S. T. Lim, C. H. Lee, H. J. Choi, and M. S. Jhon, "Solidlike transition of melt-intercalated biodegradable polymer/clay nanocomposites," Journal of Polymer Science, Part B: Polymer Physics, vol. 41, no. 17, pp. 2052-2061, 2003.

[32] M. Ganß, B. K. Satapathy, M. Thunga, R. Weidisch, P. Pötschke, and A. Janke, "Temperature dependence of creep behavior of PP-MWNT nanocomposites," Macromolecular Rapid Communications, vol. 28, no. 16, pp. 1624-1633, 2007. 

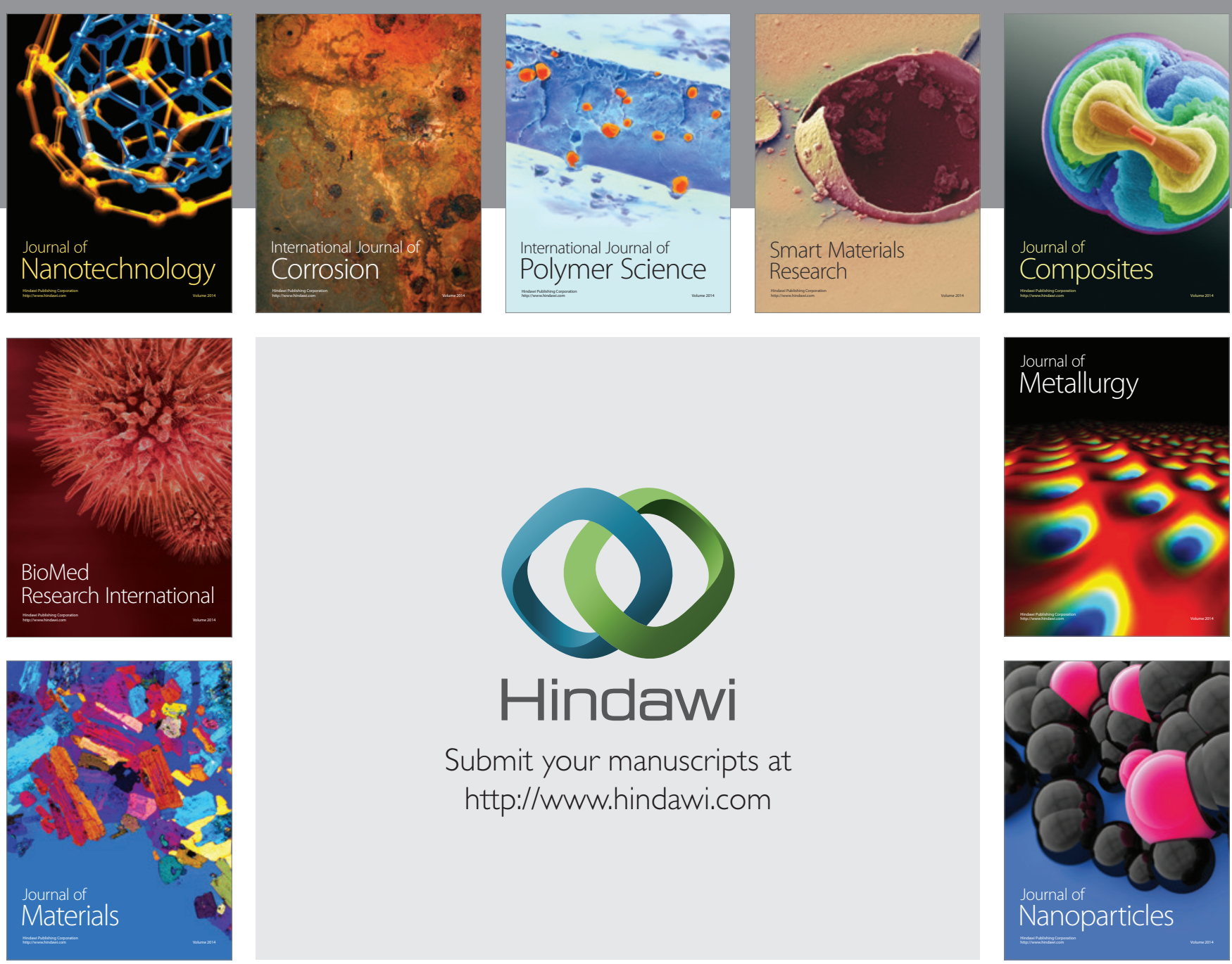

Submit your manuscripts at http://www.hindawi.com
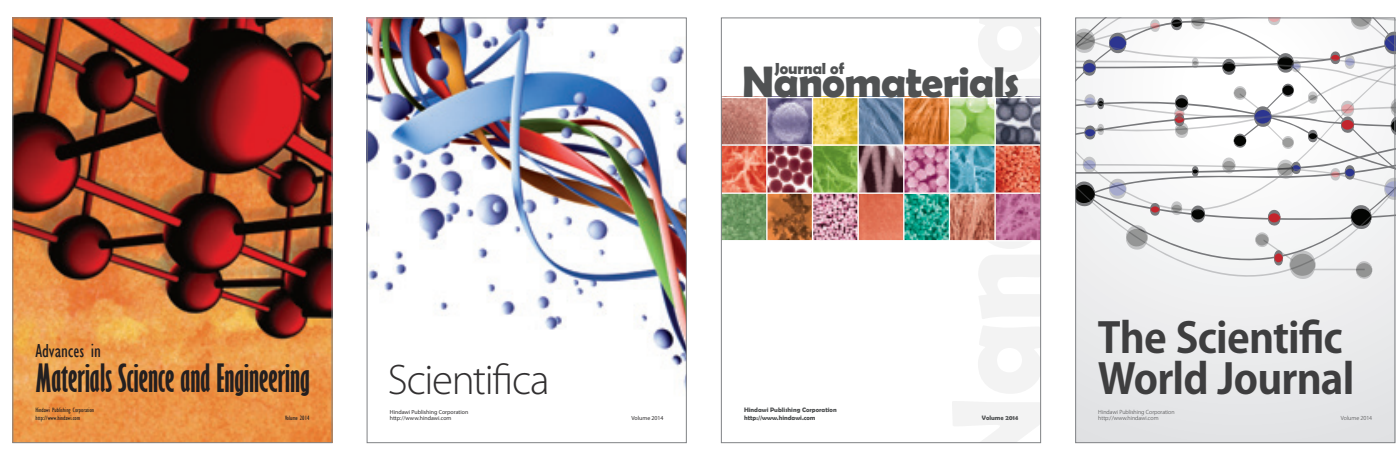

\section{The Scientific World Journal}
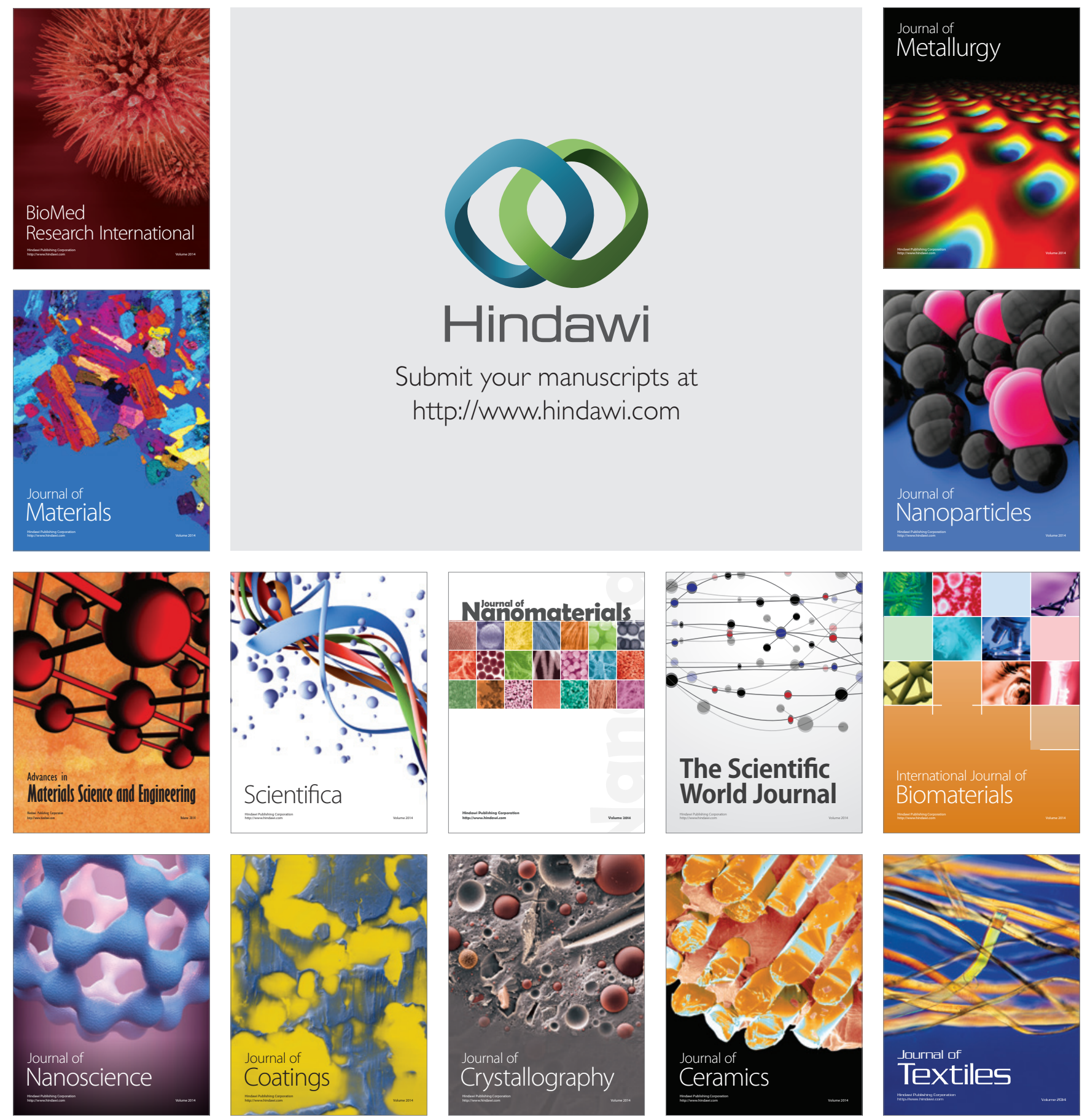